\title{
HISTÓRIA, MEIO AMBIENTE E DESENVOLVIMENTO REGIONAL DO TERRITÓRIO DO PARQUE NACIONAL DA SERRA DO ITAJAÍ NO MUNICÍPIO DE BLUMENAU (VALE DO ITAJAÍ, SANTA CATARINA)
}

Martin Stabel Garrote ${ }^{1}$

Resumo: A pesquisa aborda a temática da interação sociedade e natureza tendo como delimitação territorial a comunidade da Nova Rússia, município de Blumenau, situada na zona de amortecimento do Parque Nacional da Serra do Itajaí (PNSI). O objetivo é descrever a história ambiental e o desenvolvimento regional da comunidade. As atividades que contribuíam para o desenvolvimento regional entre 1860-1940 foram: mineração, exploração florestal (madeira e lenha) e atividades agropecuárias de subsistência. Entre 1950-1990 ocorre uma ampliação da ocupação do espaço pelas atividades exploratórias já desenvolvidas, redução da floresta nativa, introdução de pinus e eucalipto. Depois de 1990 surgem iniciativas de uso comercial, para lazer e recreação, assim como iniciativas de conservação da natureza. As atividades ampliaram-se com a criação do PNSI em 2004 e se tornaram importantes elementos do desenvolvimento regional sustentável.

Palavras-chave: História. Meio Ambiente. Desenvolvimento Regional. Parque Nacional da Serra do Itajaí, Blumenau.

\section{HISTORY, ENVIRONMENT AND REGIONAL DEVELOPMENT OF THE TERRITORY OF THE SERRA DO ITAJAÍ NATIONAL PARK IN THE MUNICIPALITY OF BLUMENAU (VALE DO ITAJAÍ, SANTA CATARINA)}

Abstract: The research deals with the theme of the interactions between society and nature, having as territorial delimitation the community of Nova Rússia, municipality of Blumenau, located in the buffer zone of the Serra do Itajaí National Park (PNSI). The objective is to describe the environmental history and the regional development of this community. The main activities that contributed to regional development between 1860-1940 were mining, forest exploration (wood and firewood), and subsistence farming activities. Between 1950-1990 there was an expansion of the occupation of space by exploratory activities already developed, and reduction of the native forest by pine and eucalyptus plantations. Beginning in the 1990s, there are initiatives for the commercial use of the region for leisure and recreation, as well as initiatives for the conservation of nature. These activities have been extended with the creation of the PNSI in 2004 and have become important elements of regional development with practices focused on sustainability.

Keywords: History. Environment. Regional Development. Serra do Itajaí National Park. Blumenau.

\footnotetext{
${ }^{1}$ Universidade Regional de Blumenau, Programa de Pós-graduação em Desenvolvimento Regional/Grupo de Pesquisa de História Ambiental do Vale do Itajaí, Blumenau-SC, Brasil, martin_stabelgarrote@yahoo.com.br, https://orcid.org/0000-0002-8034-3147

2 Universidade Regional de Blumenau, Programa de Pós-graduação em Desenvolvimento Regional/Grupo de Pesquisa de História Ambiental do Vale do Itajaí, Blumenau-SC, Brasil, frieden@furb.br, https://orcid.org/0000-0001-6021-8966
} 


\section{HISTORIA, MEDIO AMBIENTE Y DESAROLLO REGIONAL EN LO TERRITORIO DEL PARQUE NACIONAL SIERRA DEL ITAJAÍ, MUNICÍPIO DE BLUMENAU (VALLE DEL ITAJAÍ, SANTA CATARINA)}

Resumen: La investigación trata del tema acerca da interacción sociedad e naturaleza, teniendo como delimitación territorial la comunidad Nova Rússia, ubicada en la zona de amortiguamiento del Parque Nacional Serra do Itajaí (PNSI), municipio de Blumenau. El objetivo es describir la historia ambiental y analizar el desarrollo regional de esta comunidad. Las actividades que contribuyeron en el desarrollo entre 1860-1940 fueran: la minería, el corte del bosque (madeira e leña) y actividades agropecuarias de subsistencia del poblado. Entre 1950-1990 hubo una expansión de la ocupación del espacio por actividades exploratorias ya desarrolladas, y la reducción del bosque nativo por plantaciones de pinos y eucaliptos. A partir de la década de 1990, existieran iniciativas para el uso comercial de la región para el ocio y la recreación, así como iniciativas para la conservación de la naturaleza. Estas actividades se han ampliado con la creación del PNSI en 2004 y se han convertido en elementos importantes del desarrollo regional con prácticas centradas en la sostenibilidad.

Palabras clave: Historia. Medio Ambiente. Desarrollo Regional. Parque Nacional de la Sierra del Itajaí. Blumenau.

\section{Introdução}

O processo de colonização e do desenvolvimento regional no Vale do Itajaí iniciado no século XIX promoveram relações mais acentuadas entre a sociedade e a floresta. "A floresta antes ocupada e sob a interferência do nativo brasileiro recebe novos moradores e modos de vida, e de uso do mundo natural para desenvolver e progredir". A formação dos núcleos coloniais e a estrutura urbana ocupando a Mata Atlântica promoveram significativas mudanças ambientais, e a partir da segunda metade do século XX estabeleceu um mosaico de recortes de florestas, sendo que "atualmente, encontram-se melhor conservadas em áreas mais íngremes da região, de difícil acesso, como as formações que ocorrem na Serra do Itajaí" (GARROTE, SANTOS, 2016, p.01).

Uma das principais motivações para pensar a conservação no Vale do Itajaí foram as consequências visíveis no ambiente causadas pelas atividades da extração vegetal, de uso do solo, da caça e da indústria (BACCA, 2016). Essas motivações promoveram diversas ações individuais e coletivas para defender a preservação da natureza, e a criação de áreas protegidas, como a do Parque Nacional da Serra do Itajaí (PNSI). 
O PNSI é uma Unidade de Conservação de Proteção Integral criada pelo Decreto presidencial de 04 de junho de 2004. Possui uma área de 57.374 hectares, abrangendo os municípios de Indaial, Blumenau, Botuverá, Gaspar, Vidal Ramos, Guabiruba, Ascurra, Presidente Nereu, e Apiúna (Figura 1). O objetivo da criação do parque foi a conservação da Serra do Itajaí e da biodiversidade presente, ou seja, salvaguardar para as futuras gerações os recursos naturais (BRASIL, 2009).

A Lei no. 9.985 de 18 de julho de 2000 estabelece o Sistema Nacional de Unidades de Conservação da Natureza (SNUC) exigindo para as Unidades de Conservação a definição da zona de amortecimento (ZA) no seu entorno. A Zona de Amortecimento "Corresponde ao entorno imediato do PNSI, onde as atividades humanas estarão sujeitas as normas e restrições específicas". Os objetivos da ZA são os seguintes (BRASIL, 2009, p. 328)

\section{Objetivo Geral}

-Reduzir o impacto das atividades antrópicas sobre o PNSI.

Objetivos Específicos

-Promover o cumprimento das legislações ambientais vigentes para o território da Zona de Amortecimento do PNSI (ZA), sobretudo em relação às áreas de preservação permanente, às reservas legais e às supressões de vegetação.

-Contribuir com o desenvolvimento humano, atual e futuro, das populações desta ZA.

-Adequar a utilização dos recursos naturais na ZA aos parâmetros condizentes com a sustentabilidade ambiental e econômica.

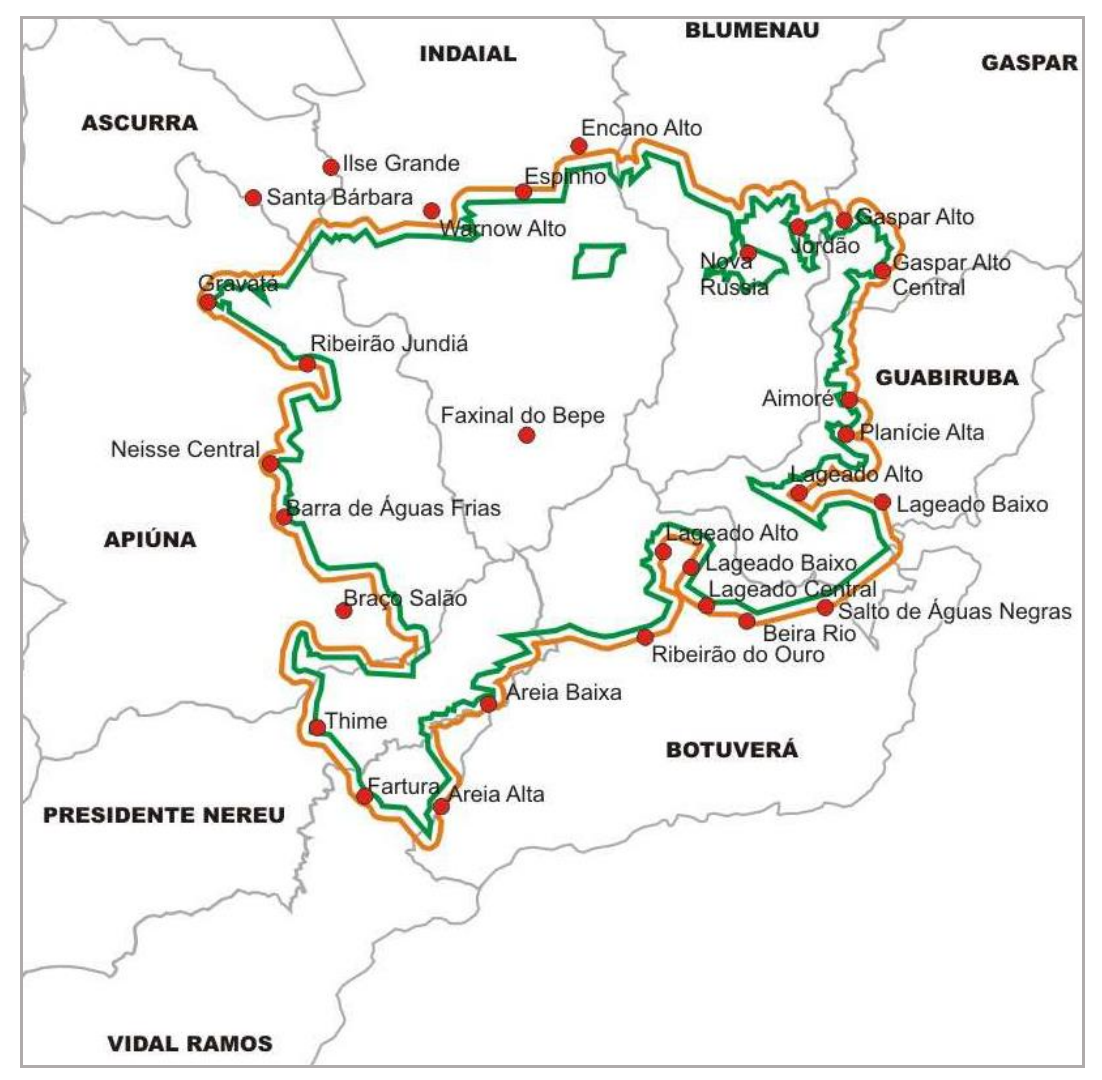


Figura 1: Comunidades localizadas no entorno e ZA do PNSI.

Fonte: BRASIL, Plano de Manejo do Parque Nacional Serra do Itajaí. Brasília: MMA. 2009. p.180.

Um dos aspectos apontados nos objetivos da ZA é o desenvolvimento sustentável. Dentre as diversas normas, uma considera que "A Zona de Amortecimento do PNSI é considerada zona rural, para os efeitos legais, não podendo ser transformada em zona urbana, de acordo com o Art. 49 da Lei No. 9.985, de 18 de julho de 2002" (BRASIL, 2009, p. 330). A zona de amortecimento do PNSI estabelece uma faixa de $500 \mathrm{~m}$ do entorno imediato do parque. Dentro desse perímetro da ZA insere-se a comunidade da Nova Rússia, localizada ao sul do município de Blumenau (Figura 1).

O PNSI localiza-se na região central do Vale do Itajaí, e é considerada uma das maiores Unidades de Conservação de Santa Catarina. Representa um dos últimos remanescentes de Floresta Atlântica, assim como conserva as nascentes de cerca de $30 \%$ dos recursos hídricos da região. Segundo Schacht e Dallacorte (2007), considerando o total da área conservada, o PNSI representa a maior área protegida da Bacia Hidrográfica do Itajaí. O território do PNSI e suas características o tornam de elevada relevância biológica, social e cultural. Apresenta um alto potencial de conservação da fauna e flora, e também abriga inúmeras nascentes fundamentais para o fornecimento de água às populações da região. $O$ parque representa um mecanismo de regulação ambiental, proporcionando controle nos ciclos pluviais e climáticos nas regiões que abrange, além de possibilitar 0 desenvolvimento de atividades de turismo e de economias sustentáveis.

"O território do parque apresenta um histórico de influências antrópicas das comunidades rurais de descendentes europeus instalados a partir de 1860, cujo desenvolvimento tem um forte vínculo com o uso dos recursos naturais" (GARROTE, SANTOS, 2016, p.2). Desenvolvimento proporcionado pela geodiversidade e biodiversidade da Floresta Atlântica como recursos de subsistência e de exploração econômica. O panorama do processo de ocupação e uso do solo no Brasil, conforme Dean (1996) causou uma drástica redução da cobertura florestal do Bioma Mata Atlântica. A partir da criação do parque em 2004, constata-se uma mudança drástica nos modos de vida das comunidades que permaneceram na zona de amortecimento e entorno do parque, ocorrendo novos processos de desenvolvimento e relações com a floresta. 
Ao longo do tempo os modos de vida das populações estabeleceram diversos usos dos recursos naturais. A sua exploração condicionou mudanças ambientais em diferentes graus de intensidade, conforme a aculturação imposta pelas necessidades de sobrevivência das comunidades e desenvolvimento da região. Esse processo faz parte da história e consiste em um importante acervo para ser estudado através da abordagem teórica e metodológica da História Ambiental. Neste sentido o objetivo da pesquisa é descrever a história ambiental e o desenvolvimento regional do território do PNSI no município de Blumenau, especificamente na comunidade da Nova Rússia. Neste contexto, identificar as diferenças nos processos de desenvolvimento promovidos antes e depois da criação do PNSI.

$\mathrm{Na}$ zona de amortecimento do PNSI localizam-se 32 comunidades com características históricas e geográficas diferenciadas. O território do parque evidencia uma diversidade de etnias que se expressam nos aspectos sociais, culturais e econômicos. O desenvolvimento das diversas comunidades está relacionado com a diversidade dos elementos naturais (variedade de formações geológicas, de relevo, de solo, de altitudes, e de condições climáticas). Assim, constroem-se diferentes histórias de ocupação, exploração e de uso dos recursos naturais de acordo com a sua localização. Enfim, a manifestação de sociodiversidade, biodiversidade e de geodiversidade constatada no território do parque é um fator relevante a ser considerado nas pesquisas de História Ambiental que condicionaram o seu desenvolvimento. Além disso, a partir da criação do parque as comunidades promoveram processos de desenvolvimento regional de forma diferenciada. Desta forma apresentam-se os resultados obtidos de uma comunidade, dadas às peculiaridades históricas e geográficas.

\section{Considerações teóricas e metodológicas}

A proposta é uma pesquisa de base, tendo como abordagem teórica a História Ambiental e o Desenvolvimento Regional para analisar de que forma ocorreu o desenvolvimento em uma comunidade situada na zona de amortecimento do PNSI. Investiga a sustentabilidade desses processos, tendo como experiência a história e a análise das relações entre sociedade e natureza locais e regionais. Considera a influência dos fatores econômicos, políticos e socioculturais no desenvolvimento regional, e a importância do PNSI nesses processos. 
A abordagem teórica e metodológica da História Ambiental insere-se na preocupação global enunciada pela questão ambiental ou ecológica. Conforme Leff (2003), a questão ambiental tornou-se um assunto relevante no cenário político, científico e educacional, como um dos maiores problemas do século XX e XXI. A partir de 1970 iniciaram-se as discussões sobre a qualidade ambiental e os impactos provocados pelo modelo desenvolvimentista. No caso do território do PNSI, pelo menos até a sua criação, consistiu em um modelo de exploração da natureza.

É primordial levar em conta a natureza, pois influencia no desenvolvimento e formação da sociedade. Deve-se considerar a forma e as consequências para a sociedade ao modificar a natureza com sua cultura material (WORSTER, 1994; DRUMMOND, 1991; LEFF, 2005; MARTINS, 2007). A ideia de fazer História Ambiental nasceu com um objetivo moral e fortes compromissos políticos. Adentra na academia e é absorvida como uma abordagem teórica de conhecer as interações sociedade e natureza pelos biólogos, antropólogos, sociólogos, historiadores, geógrafos, entre outros. A partir dos anos de 1980 os estudos de História Ambiental influenciam os pesquisadores no Brasil.

Conforme Brandt (2012, p. 18 e 19), a História Ambiental estuda "[...] as interações que as sociedades do passado tiveram com o mundo não-humano, ou seja, aquele que não foi criado pelo homem, e também com o mundo humano, repleto de objetos tanto naturais quanto artificiais, dispostos em diferentes combinações em espaços e tempos distintos". Este, contudo, é visto no sentido mais específico, onde as técnicas são um produto da cultura humana, condicionadas, elas também, pelo ambiente.

Conforme Pádua (2010), esta abordagem fornece à sociedade um conhecimento fazendo com que os sujeitos reflitam e se questionem sobre as causas que ao longo do tempo afetaram o seu ambiente e caracterizaram a sua cultura. Espindola (2015) afirma que os objetos da História Ambiental são sócio espacial, que estuda as interações das atividades humanas com o mundo natural ou como os recursos naturais conformaram a vida humana. O caráter sócio espacial investiga como as ações humanas transformaram a paisagem e como a alteraram, e quais as suas consequências para as comunidades sociais e naturais.

Fazer História Ambiental é analisar o processo histórico considerando os fatores físicos, químicos e biológicos do espaço. O território que se analisa considera a diversidade sociocultural, as transformações dos elementos naturais em recursos econômicos, avaliando as formas de usos e necessidades, e as 
consequências originadas no quadro natural e social. Analisa-se o pensamento sobre o que é o natural, suas representações e codificações simbólicas, que estabelecem o comportamento sobre o ambiente, e assim compreendendo como se dá as interações, dependências e interdependências.

Em certas situações os fatores biofísicos são decisivos. Em outras a tecnologia ou as visões de mundo podem ser decisivas. Em todas as situações, o biofísico, o social e o cultural estão presentes. Os próprios relacionamentos entre todos os componentes da interação constroem, destroem e reconstroem inúmeras formas materiais e culturais. Assim a História Ambiental e seus estudos propõe superar as divisões rígidas e dualistas entre natureza e sociedade, em favor de uma leitura dinâmica e integrativa, fundada na observação do mundo que se constrói no rio do tempo.

Para estabelecer uma análise na perspectiva do Desenvolvimento Regional Sustentável, o olhar volta-se para verificar os processos de desenvolvimento dentro de uma perspectiva teórica e metodológica da História Ambiental da comunidade de estudo. O modelo de desenvolvimento da sociedade está atrelado ao crescimento econômico que gera um colapso nas relações natureza e sociedade, desencadeando diversos processos de degradação ambiental.

Qual a relação que pode ser estabelecida entre a História Ambiental e o Desenvolvimento Regional? Como a História Ambiental produz conhecimento a respeito do uso dos recursos naturais (biodiversidade e geodiversidade) pela sociedade humana, esta pode contribuir no planejamento de políticas públicas de desenvolvimento sustentável. Conforme Garrote e Santos (2016, p. 01), com "os estudos da História Ambiental é possível averiguar as limitações e vocações dos territórios obtendo informações uteis para orientar processos de desenvolvimento sustentável”.

No Vale do Itajaí, a partir do século XIX, diversas comunidades se instalaram seguindo diversos cursos de água, e que durante sua história de convivência mantiveram diversas interações com a Floresta Atlântica. Os imigrantes europeus acentuaram as transformações da paisagem do Vale do Itajaí ao longo do tempo, caracterizando-a conforme o modelo de desenvolvimento. Isto condiz com a afirmação de Milton Santos (1994, p. 66), de que "A paisagem não se cria de uma só vez, mas por acréscimos, substituições; a lógica pela qual se fez um objeto no passado era a lógica de produção daquele momento. Uma paisagem é uma escrita 
sobre a outra, é um conjunto de objetos que tem idades diferentes, é uma herança de muitos diferentes momentos".

As diversas culturas se formaram e se desenvolveram e, ainda, necessitam do uso dos recursos naturais. Os problemas sociais e ambientais atuais estão relacionados historicamente da forma como a sociedade vê e age sobre a natureza, tornando-se primordial a criação de unidades de conservação. Tendo em vista essa abordagem, a pesquisa foi desenvolvida em três etapas. Na primeira etapa foi realizado um levantamento e revisão de dados em jornais, documentos oficiais, atlas, mapas, transcrições de entrevistas, material audiovisual, trabalhos acadêmicos como relatórios de pesquisas, artigos científicos em periódicos, monografias, dissertações, teses e anais de eventos científicos. Este levantamento contribuiu para compreender os aspectos bióticos e abióticos do território do PNSI, e historiar o processo de ocupação humana e uso do solo/natureza. As saídas de campo foram fundamentais para entender e analisar a configuração da paisagem atual, e estabelecer a relação do tempo presente com o processo histórico do desenvolvimento da região.

$\mathrm{Na}$ segunda etapa foram realizados levantamentos de dados em documentos oficiais, como o Plano de Manejo do Parque Nacional da Serra do Itajaí (BRASIL, 2009). Assim como foram analisadas transcrições de entrevistas de História Oral desenvolvidas nas pesquisas dos autores, e que compõe o acervo do banco de dados do GPHAVI (Grupo de Pesquisa de História Ambiental do Vale do Itajaí). $\mathrm{Na}$ terceira etapa foram separados os dados das etapas anteriores, e estes analisados hermeneuticamente.

\section{Resultados e Discussões}

No território do parque predomina a Mata Atlântica Ombrófila Densa que "ocupa as encostas do Vale do Itajaí em altitudes que variam de 30 a $400 \mathrm{~m}$, nos diversos municípios do baixo e médio vale" (SCHÄFFER; PROCHNOW, 2002, p. 88). A floresta apresenta grande pujança, com árvores de mais de $30 \mathrm{~m}$ de altura, não qual o verde intenso é marcante. As condições climáticas (temperaturas amenas, pluviosidade intensa e bem distribuída) favoreceram e condicionaram a paisagem antes da colonização. A variedade de espécies que compõem a floresta é imensa, entre árvores, arbustos, pteridófitos terrícolas e epífitos de "uma riqueza inestimável" (SCHÄFFER; PROCHNOW, 2002, p. 88). Foi uma paisagem assim 
como a descrita, que os primeiros imigrantes encontraram ao adentrarem o Vale do Itajaí, e na região do PNSI.

A região é repleta de vales, montanhas e morros que dificultam a efetivação da prática agrícola que inicialmente teve muita dificuldade em se estabelecer com grande produtividade. As áreas ocupadas pela agricultura são várzeas temporais do excesso hidrológico em períodos de alta pluviosidade. É nessas áreas planas que a produção de subsistência entre os moradores se configurava como uma das principais atividades.

Antes da colonização e uso do solo para o desenvolvimento das comunidades, era comum encontrar nas montanhas e várzeas árvores como Canela, Peroba, Cedro além de espécies outras que formavam uma gama imensa de variedades da flora da região. As árvores encontradas possuíam troncos com diâmetro significativo, o que posteriormente seria importante para a procura da madeira para exploração dos colonos. Depois da retirada da mata - madeira para uso e comercialização -, as áreas foram ocupadas pela produção agrícola para plantio de subsistência e posteriormente com a monocultura de fumo, pinus e eucalipto.

A vegetação atualmente encontrada nas vertentes íngremes é de capoeirinha, capoeira, capoeirão e alguns pequenos retalhos de mata secundária que não possuem mais de 30 anos de existência devido à retração do uso do solo para cultivo. Na paisagem também é notório a expansão do cultivo de pinus e eucalipto. $A$ água representa um elemento vital para o desenvolvimento da região. Nas comunidades os cursos de água, muitas vezes, foram desviados para o benefício de alguma família ou produção agrícola.

Os novos moradores da floresta estabeleceram formas de relação e de exploração dos recursos naturais com as novas condições aqui encontradas, mesclando seus saberes com o modo de vida do caboclo. Adaptavam o meio para que se parecesse mais com o meio europeu. Isso provocou em grande escala atividades como a caça, pesca e uso da madeira para as mais diversas finalidades, criando manifestações culturais como os clubes de caça e tiro e festas de caça. Conforme Santos (2011), um dos principais interesses para a colonização da região sul do Brasil a partir de 1850 foi a possibilidade de privatizar e comercializar as terras florestais.

Segundo Cervi (2009), a expectativa do presidente da Província de Santa Catarina era de que o rio Itajaí, cujo delta se localiza na colônia de Itajaí, tivesse 
uma ligação com o planalto serrano, mais especificamente na região de Lages, que já possuía certa prosperidade no final da década de 1830. Com o intuito de promover a colonização do vale é criada a Lei Imperial no 11 de 5 de maio de 1835 , que orientava os tamanhos dos lotes, prazos de pagamentos dos empréstimos feitos aos colonos e outras organizações que dependiam das decisões imperiais.

Os primórdios da ocupação do território do Vale do Itajaí ocorrem pelo litoral nas margens do Rio Itajaí e de seus afluentes a partir de 1835, sendo a primeira colônia a de Itajaí. Seus integrantes foram brasileiros e estrangeiros, oriundos do arquipélago dos Açores, Madeira, do Rio Grande do Sul e São Paulo, e posteriormente grupos de imigrantes do Sacro Império Romano-Germano, incluindo nacionalidades alemãs, polonesas, suíças entre outros povos. O território era habitado pelos indígenas Xokleng/Laklano e Kaigangs até o interior, e do povo Tupy no litoral, além de pequenos grupos nômades que viviam na floresta (SIEBERT, 1997). Por muito tempo esses indígenas lutaram por suas terras com os novos colonizadores, cuja presença causava um entrave ao progresso das colônias da Bacia do Itajaí, confronto que resultou no extermínio das culturas nativas (SILVA, 1972).

O Vale do Itajaí começa uma grande transformação com o estabelecimento da Colônia Blumenau em 1850. Os imigrantes viam a natureza como um inimigo a ser desbravado e dominado para o estabelecimento dos moldes civilizatórios europeus (MATTEDI, 2001). De acordo com Siebert (1997), os colonos consideravam a natureza um grande problema e as matas densas eram vistas como empecilho para o progresso, devendo ser feita sua retirada para que os lotes fossem traçados e vendidos, e colocados em funcionamento para o desenvolvimento.

A partir da colonização da foz ao alto vale, segundo Siebert (1997), diversos núcleos coloniais constituíram-se no entorno dos diversos cursos de água da Bacia do Itajaí. O ideal desbravador foi sendo construído ao longo dos anos com objetivo evidente de valorização dos imigrantes como os responsáveis diretos por estas conquistas (SANTOS, 2011). A gradativa exploração da floresta e o constante crescimento populacional e econômico causaram a redução de sua cobertura arbórea em toda a região, agravando os atuais problemas ambientais (enchentes, deslizamentos de terra, enxurradas) constatados no Vale do Itajaí, que se manifestaram ao longo do tempo mais frequentes e intensos.

Próximo a Serra do Itajaí, conforme Garrote, Dambrowski e Santos (2009), na região que hoje pertence ao Parque Nacional da Serra do Itajaí, desenvolveram-se 
mais de 30 pequenos núcleos coloniais de descendentes europeus de vocação agrícola que vieram pelos fluxos dos núcleos de colonização. Estas comunidades passaram a se formar e desenvolver na região da Serra do Itajaí a partir de 1860 através de dois fluxos de colonização. Um deles partiu da Colônia Blumenau (Rio Itajaí-açú), ocupando e formando as comunidades que hoje entornam o PNSI em Indaial, Ascurra, Apiúna, Presidente Nereu e Vidal Ramos. O outro fluxo partiu de Brusque (Rio Itajaí-mirim) para ocuparem a região de Porto Franco, hoje Botuverá, até chegar a Vidal Ramos. A colonização ocorre a montante das referidas colônias e se consolida no início do século XX.

A comunidade da Nova Rússia está assentada num alvéolo estreito, caracterizado por um relevo levemente ondulado em rochas granito-gnáissicas (faixa). É atravessada transversalmente pelo Rio Garcia, sendo que na margem esquerda tem como afluente o Ribeirão Minas de Prata que acompanha o contato tectônico da faixa com o Grupo Itajaí (formação sedimentar) evidenciada por falha geológica.

De acordo com Garrote, Dambrowski e Santos (2009), a comunidade da Nova Rússia foi composta por imigrantes prussianos, alemães, suíços, italianos e brasileiros. Mas antes desses imigrantes chegarem ao local, o território era frequentado por indígenas Xokleng/Lakano. No ano de 1830 ingleses acompanhados de um escravo procuraram ouro nas proximidades da atual comunidade, mas desistiram devido às dificuldades do relevo íngreme e dos ataques indígenas. O escravo retorna dez anos depois com algumas famílias que ao se estabelecerem constroem moradias feitas de palmitos, xaxins, imbaúbas e caeté; e a sua principal fonte de renda foi o plantio de espécies exóticas como a banana e cana de açúcar; e de carvão e algumas pepitas de ouro.

A partir de 1890 as primeiras empresas de mineração atuam na região com abertura de túneis nas encostas do Ribeirão Minas de Prata. No processo de exploração usaram dinamite para obter minérios como a prata, chumbo, e zinco combinados com enxofre, e alguns pontos de alto teor metálico. Essas empresas eram de origens russas, argentinas e alemãs que promoveram um grande atrativo, junto com as serrarias, de emprego e desenvolvimento regional (GARROTE, DAMBROWSKI, SANTOS, 2009).

Os recursos das minas "foram explorados até se esgotarem ou se tornarem inviáveis economicamente, o que culminou no êxodo de grande parte da população residente naquela época (década de 40)." (BRASIL, 2009, p. 87). Atualmente 
algumas minas apresentam a sua entrada obstruída pelos deslizamentos de terra, enquanto que outras ainda permitem a sua entrada. As Minas da Prata se destaca como "um local de relevante interesse turístico pela forte representação histórica [...], sendo necessários estudos relacionados à viabilidade das mesmas, para que seja determinada sua adequada inserção no programa de uso público do PNSI." (BRASIL, 2009, p. 87), e servir de atrativo turístico para contribuir no desenvolvimento da comunidade.

A agricultura de subsistência se perpetuou por muitos anos, assim como a caça para a própria alimentação. Na década de 1950 foi aberta uma nova via para chegar até o local, a Rua Santa Maria, e através dela escoavam a produção das madeireiras. Na década de 1970 inicia outro êxodo rural, com o abandono gradual da atividade agrícola pela fabril. Os descendentes mais jovens partem para a cidade em busca de emprego.

Em 1988 a Companhia Artex com a iniciativa do ambientalista e ecólogo Lauro Bacca cria o Parque Ecológico Artex com a finalidade de preservar a região. Entretanto, dez anos após a sua criação as terras são repassadas para a coordenação da Fundação do Meio Ambiente do Município de Blumenau (FAEMA) e Universidade Regional de Blumenau, pois com a recessão da indústria têxtil não foi possível dar continuidade à manutenção do parque. Assim é criado o Parque Natural Municipal "Nascentes do Garcia” pela Lei n. 4990/98. A década de 1990 também é marcada por uma legislação ambiental brasileira mais rigorosa que dificulta o corte e a exploração da Mata Atlântica, caso do decreto $n^{\circ} 99.547$ de 1990, e posteriormente o decreto $\mathrm{n}^{\circ} 750$ de 1993, que revoga o anterior.

A proibição da caça e da exploração de madeira a partir da década de 1990 gera uma estabilidade demográfica na Nova Rússia. Essas atividades antrópicas causaram diversos impactos ambientais na região, sendo as madeireiras as grandes responsáveis pela retirada da cobertura vegetal e matas ciliares, propiciando desastres como deslizamentos de terra, erosões das margens, assoreamento dos cursos de água, e enchentes (GARROTE, DAMBROWSKI, SANTOS, 2009).

A partir dos problemas advindos da degradação ambiental, alguns grupos da comunidade questionam o processo de exploração dos recursos naturais. Implica um início da necessidade de mudanças do modelo de desenvolvimento adotado na região. Através da participação da comunidade, alguns setores da sociedade se organizaram em benefício do desenvolvimento local, que a princípio não tangem a sustentabilidade. 
Surgiram na comunidade casas de veraneio, alguns bares, e recantos de lazer usando os recursos hídricos. Nos anos oitenta, setores e movimentos sociais refletem sobre a necessidade da criação de um parque nacional na região da Serra do Itajaí. A partir de sua criação em 2004 ocorre uma mudança drástica nos modos de vida das comunidades localizadas na zona de amortecimento, que desencadeia novos processos de desenvolvimento e relações com a floresta na comunidade da Nova Rússia.

Graças às potencialidades dos elementos naturais e a necessidade de preservação da natureza, as atividades econômicas direcionam-se cada vez mais para a sustentabilidade. O turismo e o lazer destacam-se com pequenos empreendimentos substituindo as áreas agrícolas. A presença de cachoeiras em algumas propriedades tem servido de elemento atrativo para recantos naturais, que oferecem estrutura de restaurante, quiosque com churrasqueiras, camping, chalé e outros serviços. Para hospedagem a Pousada Rio da Prata "com muitas espécies de animais e vegetais, várias nascentes e ribeirões de águas límpidas e cristalinas de beleza rara, [...] O nome da Pousada 'Rio da Prata' originou-se do rio que transportava o minério no início do século $X X$, quando a região sofreu forte exploração madeireira e mineral." (BRASIL, 2009, p. 87).

Para ressaltar a importância ambiental da região, o Ecomuseu Dr. Agobar Fagundes, situado no Ribeirão Minas de Prata, tem como objetivo:

[...] promover junto à comunidade, pesquisas sócio-histórico-culturais com pesquisadores de diferentes áreas do conhecimento, através de grupos de trabalho, oficinas, cursos de educação patrimonial, engenharia ambiental, entre outros. A preservação do patrimônio natural da região é objeto matriz e, a partir dela, estendem-se as possibilidades de crescimento e valorização da vida para além dos territórios (BRASIL, 2009, p. 87-88).

O desenvolvimento da comunidade incorporou outras atividades econômicas sustentáveis, pois "existem famílias que praticam a agricultura orgânica, com produção de doces, geléias, pães, licores, dentre outros, o que vem a complementar a renda dessas famílias." (BRASIL, 2009, p. 88).

A exploração das florestas levou a uma grande redução da biodiversidade, mas a região ainda é muito rica em flora e fauna conforme estudos do Plano de Manejo do PNSI (BRASIL, 2009). As iniciativas governamentais ou privadas são importantes para a manutenção das populações humanas na área rurais associadas 
às alternativas de produção menos impactantes como a produção orgânica e a permacultura.

\section{Considerações Finais}

A leitura do processo de ocupação e uso dos recursos naturais sob a perspectiva da História Ambiental e do desenvolvimento regional do território do PNSI permite identificar quatro períodos na comunidade da Nova Rússia. O primeiro (1860 até a década de 1940) é marcado pela colonização, organização da comunidade e do modo de vida rural, implantação dos processos de desenvolvimento (artesanal e manufatura). Destacam-se a mineração, a exploração florestal (madeira e lenha), e áreas de pasto e de agricultura. A partir da mineração, o local recebe mais morador e ocorre aumento do uso do solo, caça e extração vegetal. A decadência da mineração nos anos de 1940 gera um êxodo na comunidade.

No segundo período (década de 1950 até 1990) a modernização com a incorporação de novas tecnologias na atividade madeireira, como o uso da moto serra e melhorias na linha de produção, intensificaram a extração vegetal e desmatamento na região. Há continuidade das atividades de subsistências dos colonos, agricultura e caça. As áreas de cultivos de pinus e eucalipto reduzem a cobertura florestal nativa. O êxodo rural na década de 70 representa a demanda de emprego nas indústrias de Blumenau. $O$ final do período representa uma preocupação dos processos de degradação ambiental.

No terceiro período (1990 a 2004) as influências das legislações ambientais que restringe o corte da Mata Atlântica no início da década de 90 e a criação do Parque Natural Municipal "Nascentes do Garcia" mudam as práticas das atividades socioeconômicas. Diminuem os processos de exploração, e na região é iniciado um processo de proteção e conservação da Serra do Itajaí, com a criação do PNSI em 2004.

A partir de 2004, quarto período, desenvolvem-se atividades socioeconômicas mais sustentáveis, ou seja, novos empreendimentos e processos de desenvolvimento adaptaram-se à nova realidade e passam a utilizar das caraterísticas naturais como atrativo para as atividades econômicas. Portanto, constatam-se práticas distintas de desenvolvimento antes e depois da criação do parque. 
A História Ambiental da comunidade da Nova Rússia é marcada em sua grande parte pela exploração da natureza atrelada a uma visão na qual os recursos naturais seriam infinitos. O modelo de desenvolvimento modificou a paisagem de floresta para áreas de cultivo de monoculturas, moradias rústicas e engenhos, pastos e reflorestamentos. Associado a isso a caça e coleta de palmito era um elemento presente na vida do colono. A exploração encadeou o processo de acumulação de energia e matéria, e promoveu o crescimento econômico, havendo maior adensamento de pessoas enquanto duraram as principais atividades, a mineração e a exploração da madeira.

A partir de 1990 com as novas leis sobre a Mata Atlântica os processos de exploração e transformação de elementos da biodiversidade em recursos naturais foram gradualmente diminuindo. Com a criação do PNSI as práticas, e até mesmo o pensamento a respeito da importância da natureza mudaram, e resultaram, em grande parte por iniciativa de pessoas que passaram a ter propriedades no local, alterações nos processos de desenvolvimento. As propriedades produtivas diminuem ao passo que surgem pousadas, recantos, sítios e chácaras.

A história da Nova Rússia demonstra também como uma comunidade de perfil agrícola, dependente da exploração da natureza muda a partir da criação de um parque nacional, no caso o PNSI. E demonstra como uma Unidade de Conservação pode ser utilizada como um instrumento que possibilita conciliar o desenvolvimento e a preservação como estratégia eficiente, sustentável e socialmente justa, garantindo crescimento econômico segundo um modelo em que a economia e a natureza sejam tratadas como elementos complementares, e não antagônicos.

Conservar a biodiversidade garante não apenas mais crescimento, mas, principalmente, melhor crescimento, ou um processo de desenvolvimento mais sustentável

\section{REFERÊNCIAS}

BACCA, Lauro E. Diagnóstico preliminar dos aspectos históricos do Parque Nacional Serra do Itajaí (PNSI). Disponível em: < http://www.acaprena.org.br/planodemanejo/result hist.asp >. Acesso em: 03 ago. 2016.

BRANDT, Marlon. Uma história ambiental dos campos do planalto de Santa Catarina. 2012. 332 f. Tese (Doutorado em História Cultural)-Centro de Filosofia e Ciências Humanas Universidade Federal de Santa Catarina, Florianópolis, 2012.

BRASIL. Decreto presidencial de 04 de junho de 2004. Cria o Parque Nacional Serra do Itajaí. Diário Oficial da União. Brasília, 07 de junho de 2004. 
BRASIL. Lei no. 9.985 de 18 de julho de 2000. Institui o Sistema Nacional de Unidades de Conservação. Diário Oficial da União. Brasília 19 de julho de 2000.

BLUMENAU. Lei no 4.990 de 03 de junho de 1998. Cria o Parque Natural Municipal Nascentes do Garcia. Disponível em: https://leismunicipais.com.br/a/sc/b/blumenau/leiordinaria/1998/499/4990/lei-ordinaria-n-4990-1998-cria-o-parque-natural-municipalnascentes-do-garcia-e-da-outras-providencias Acesso em abril de 2018.

BRASIL. Decreto no 99.547 de 25 de setembro de 1990. Dispõe sobre a vedação do corte, e da respectiva exploração, da vegetação nativa da Mata Atlântica, e dá outras providências. Diário Oficial da União. Brasília 28 de setembro de 1990.

BRASIL. Decreto no 750 de 10 de fevereiro de 1993. Dispõe sobre o corte, a exploração e a supressão de vegetação primária ou nos estágios avançado e médio de regeneração da Mata Atlântica, e dá outras providências. Diário Oficial da União, Brasília 11 de fevereiro de 1993.

BRASIL. Plano de Manejo Parque Nacional da Serra do Itajaí. Brasília: MMA:ICMBIO, 2009.

CERVI, Pedro G. A diversidade da colonização do Vale do Itajaí: 1835-1867. Revista Santa Catarina em História, Florianópolis, v. 1, n. 2, p. 16-30, 2009.

DEAN, Warren. A ferro e fogo: a história e a devastação da mata atlântica brasileira. São Paulo: Companhia das Letras, 1996.

DRUMMOND, José Augusto. A História Ambiental: temas, fontes e linhas de pesquisa. Estudos Históricos. Rio de Janeiro, vol.4, n. 8, 1991, p.177-197.

ESPINDOLA, Haruf S. A problemática espacial e a história ambiental. Revista de História Regional, Ponta Grossa, v. 20, n. 2, p. 343-374, 2015.

GARROTE, Martin S.; DAMBROWSKI, Vanessa; SANTOS, Gilberto F. dos. Antropismo no processo histórico de ocupação da Floresta Atlântica na região e entorno do Parque das Nascentes em Blumenau-SC. In: SIMPÓSIO NACIONAL DE HISTÓRIA, 25., 2009, Fortaleza. Anais ..., Fortaleza: UFC, 2009. Disponível em http://anais.anpuh.org/wpcontent/uploads/mp/pdf/ANPUH.S25.0022.pdf Acesso em abril de 2008.

GARROTE , Martin Stabel; SANTOS, Gilberto Friedenreich dos. A Contribuição da História Ambiental para o Desenvolvimento Sustentável. In: SEMINÁRIO DE DESENVOLVIMENTO REGIONAL, Anais... Blumenau: FURB, 2016. Disponível em: , https://drive.google.com/open?id=0B-k8QeFAxvrvdFFmLTVGY2tJTkk> Acesso em abril de 2008.

GARROTE, Martin Stabel; SANTOS, Gilberto Friedenreich. Construindo a História Ambiental do Parque Nacional da Serra do Itajaí. In: Encontro Estadual de História, XVI. 2016, Chapecó. Anais do ... Chapecó: ANPUH. 2016. Disponível em: <http://www.encontro2016.sc.anpuh.org/resources/anais/43/1464662762 ARQUIVO Artigo MSGANPUH2016.pdf> Acesso em abril de 2008.

LEFF, E. A complexidade ambiental. São Paulo: Cortez, 2003.

LEFF, Enrique. Construindo a História Ambiental da América Latina. Revista Esboços, Florianópolis, n.13, p.11-30, 2005.

MARTINS, Marcos Lobato. História e meio ambiente. São Paulo: Annablume; Faculdades Pedro Leopoldo, 2007. 
MATTEDI, Marcos A. Notas sobre as visões de natureza em Blumenau: mais um capítulo da trágica historia do sucesso humano. Revista de estudos ambientais, v. 3, n. 1, jan./abr, p. 29-39, 2001.

PÁDUA, José A. de. As bases teóricas da história ambiental. Revista Estudos Avançados, São Paulo, v. 24, n. 68, p. 81-101, 2010.

SANTOS, Milton. Metamorfoses do espaço habitado. 3. ed., São Paulo: Hucitec, 1994.

SANTOS, Manoel Pereira Rego Teixeira dos. O imigrante e a floresta: transformações ambientais, das práticas e da produção rural nas colônias do Vale do Itajaí-SC. 2011. 218 f. Tese (Doutorado em História)-Centro de Filosofia e Ciências Humanas, Universidade Federal de Santa Catarina, Florianópolis. 2011.

SCHACHT, Karin; DALLACORTE, Fabiana. As Comunidades e o Parque Nacional da Serra do Itajaí. Blumenau: Associação Catarinense de Preservação da Natureza, 2007.

SCHÄFFER, W. B. \& PROCHNOW, M. A Mata Atlântica e você: como preservar, recuperar e se beneficiar da mais ameaçada floresta brasileira. Brasília: APREMAVI, 2002.

SIEBERT, Claudia F. Estruturação e desenvolvimento da rede urbana do Vale do Itajaí. Blumenau: FURB, 1997.

SILVA, José F. História de Blumenau. Florianópolis: Edeme, 1972.

WORSTER, Donald. Nature s Economy: a history of ecological ideas. Second Edition, New York: Cambridge University Press, 1994.

\section{NOTAS DE AUTOR}

\section{CONTRIBUIÇÃO DE AUTORIA}

Martin Stabel Garrote - Concepção da pesquisa. Coleta e análise dos dados. Elaboração do manuscrito. Revisão e aprovação da versão final do trabalho.

Gilberto Friedenreich dos Santos - Participação na coleta dos dados. Orientação na elaboração do manuscrito. Participação ativa da discussão dos resultados; Revisão e aprovação da versão final do trabalho.

\section{FINANCIAMENTO}

O presente trabalho foi realizado com recursos materiais obtidos em pesquisa financiada pela Fundação de Amparo a Pesquisa e Inovação do Estado de Santa Catarina - FAPESC, através da Chamada Pública Universal 07/2009; Através de financiamento de Bolsa pela Coordenação de Aperfeiçoamento de Pessoal de Nível Superior - CAPES - Código de Financiamento 001 no financiamento de bolsa no doutorado. E apoio de equipamentos e recursos materiais oriundos do Grupo de Pesquisas de História Ambiental do Vale do Itajaí, e do Programa de Pós-Graduação em Desenvolvimento Regional, ambos da Universidade Regional de Blumenau.

CONSENTIMENTO DE USO DE IMAGEM

Não se aplica

APROVAÇÃO DE COMITÊ DE ÉTICA EM PESQUISA

Não se aplica.

CONFLITO DE INTERESSES

Não existem conflitos de interesses.

\section{LICENÇA DE USO}

Este artigo está licenciado sob a Licença Creative Commons CC-BY. Com essa licença você pode compartilhar, adaptar, criar para qualquer fim, desde que atribua a autoria da obra.

\section{HISTÓRICO}

Recebido em: 09-02-2017

Aprovado em: 09-09-2018 